\title{
Alleviation of Thermoinhibition in Preconditioned Lettuce Seeds Involves Ethylene, Not Polyamine Biosynthesis
}

\author{
Xue-Lin Huang and Anwar A. Khan ${ }^{2}$ \\ New York State Agricultural Experiment Station, Cornell University Geneva, NY 14456
}

Additional index words. Lactuca sativa, matriconditioning, osmoconditioning, secondary dormancy, thermoinhibition, thermodormancy, supraoptimal temperature

\begin{abstract}
Preconditioning 'Mesa 659' lettuce (Lactuca sativa L.) seeds with the moist solid carrier Micro-Cel E at 15C for 20 hours removed thermoinhibition and allowed the seeds to germinate at 35C. Participation of 1-aminocyclopropane-1-carboxylic acid (ACC) and its use in the removal of thermoinhibition were indicated from the following: a) the $\mathrm{ACC}$ level in the preconditioned seeds peaked before germination at $35 \mathrm{C}$; b) addition of aminoethoxyvinylglycine (AVG), an inhibitor of ACC synthesis, reduced the $\mathrm{ACC}$ level and inhibited germination at 35C; c) response of preconditioned seeds to ethylene at 35C preceded that of $\mathrm{ACC}$; d) exogenous $\mathrm{ACC}$, (2-chloroethyl) phosphonic acid (ETH, ethephon), or ethylene reversed the inhibitory effect of AVG and restored the capability of the seed to germinate at $35 \mathrm{C}$; e) $\mathrm{Co}^{+2}$, an inhibitor of the ACC-to-ethylene step, partially inhibited germination of preconditioned seeds at 35C, and the effect was reversed by ETH. The major free polyamines in dry seed were spermidine (Spd) and putrescine (Put). An increase in polyamine level occurred following transfer of conditioned seeds to 35C. Of the various polyamine biosynthesis inhibitors, difluoromethylarginine and cyclohexylammonium sulfate inhibited an increase in Spd and Put levels only after germination, whereas difluoromethyorinthine had no effect on polyamine biosynthesis. None of these inhibitors affected the relief of thermoinhibition. Thus, the increase in polyamine level during germination at $35 \mathrm{C}$ does not appear to be associated with the alleviation of thermoinhibition.
\end{abstract}

Inhibition of lettuce seed germination at supraoptimal temperatures (thermoinhibition) leads to induction of a secondary dormancy (thermodormancy) (Khan, 1980/81). Preplant seed hydration with water, salt solution, or moist solid carriers, termed physiological conditioning, confers various degrees of thermotolerance to lettuce and other seeds, enabling them to germinate at high temperatures (Khan, 1992). A 20 -h presoak in $1 \% \mathrm{~K}_{3} \mathrm{PO}_{4}$ at $15 \mathrm{C}$ was more effective than a similar soak in water for alleviating thermoinhibition in 'Minetto' lettuce seeds (Cantliffe et al., 1984). Moist solid carriers with high matric potential have been used recently to precondition (matricondition) lettuce and other seeds to improve germination at high temperatures (Khan, 1992). 'Mesa 659' lettuce seeds, presoaked on moist Micro-Cel E (a synthetic calcium silicate), consistently germinated above $80 \%$ at 35C (Khan et al., 1990). The biochemical basis for the relief of thermoinhibition (thermotolerance) remains unclear.

Ethylene synthesis and action have been implicated in the alleviation of high temperature, osmotic restraint, and salinity on lettuce seed germination (Abeles, 1986; Khan and Huang, 1988; Saini et al., 1986). A synergistic or an additive effect between ACC and cytokinin in the alleviation of thermoinhibition and ethylene production has been demonstrated recently

Received for publication 4 Nov. 1991. Accepted for publication 13 Apr. 1992. This research was supported in part by a grant form the Ferry Morse Seed Co., Modesto, Calif. We gratefully acknowledge samples of difluoromethylornithine and difluoromethylarginine from Eckkehard H. Bohme, Merrell Dow Research Institute, Cincinnati; aminoethoxyvinylglycine from Hoffman-La Roche, Nutley, N.J.; Micro-Gel E from Manville Products Corp., Denver; (2-chloroethyl) phosphonic acid from Union Carbide, Modesto; and 'Mesa 659' lettuce seeds from Harris-Moran Seed Co., Rochester, N.Y. The cost of publishing this paper was defrayed in part by the payment of page charges. Under postal regulations, this paper therefore must be hereby marked advertisement solely to indicate this fact.

'Visiting Fellow, Dept. of Horticultural Sciences. Present address: Dept. of Biology, Zhongshan Univ., Guangzhou, People's Republic of China.

${ }^{2}$ Professor, Dept. of Horticultural Sciences. in lettuce seeds (Khan and Prusinski, 1989), suggesting that enhanced use of ACC is possible during the alleviation.

Active metabolism of polyamines has also been noted during germination of seeds (Scoccianti et al., 1990; Torrigiani et al., 1988). Since both ethylene and polyamines share S-adenosylmethionine (SAM) as a common precursor (Miyazaki and Yang, 1987), their biosyntheses are interrelated. Polyamine level and activities of polyamine biosynthetic enzymes may increase in response to plant stresses, including high-temperature stress (Das et al., 1987). Although the relationship between stress responses of seedlings or vegetative plant tissues and polyamine content has been extensively studied (Rabe, 1990), to our knowledge, nothing is known about changes in polyamines during early seed germination under stressful conditions.

We investigated whether ACC and polyamines are involved in the removal of thermoinhibition in lettuce seeds preconditioned at $15 \mathrm{C}$ and attempted to determine by means of specific inhibitors which step(s), if any, in the ethylene and polyamine biosyntheses are involved in the prevention of thermoinhibition.

\section{Materials and Methods}

Seed preconditioning and germination. 'Mesa 659' lettuce (1988 harvest) seeds held at 7C and 28\% relative humidity (RH) were preconditioned in batches of $2 \mathrm{~g}$ with the moist solid carrier Micro-Cel E (Khan et al., 1990). The seed : Micro-Cel E : water or test solution ratio (by weight) in the preconditioning mixture was 1:0.25:1.5. After mixing the contents of the mixture in 0.43-liter glass jars, the jars were loosely capped and held at $15 \mathrm{C}$ for 4 to $20 \mathrm{~h}$ under fluorescent light (16 $\left.\mu \mathrm{mol} \cdot \mathrm{m}^{-2} \cdot \mathrm{s}^{-1}\right)$. After this preconditioning, seeds were washed with running water to remove the carrier and blotted dry. Fifty

Abbreviations: ACC, 1-aminocyclopropane-1-carboxylic acid; AVG, aminoethoxyvinylglycine; CHAS, cyclohexylammonium sulfate; DFMA, difluoromethylarginine; DFMO, difluoromethyornithine; ETH, (2-chloroethyl) phosphonic acid; Put, putrescine; Spd, spermidine; Spm, spermine. 
or 100 dry or preconditioned seeds (four or six replicates) were soaked with $3 \mathrm{ml}$ of water or test solution in $5.0-\mathrm{cm}$ petri dishes lined with two layers of Whatman No.1 filter paper and germinated at 25 or $35 \mathrm{C}$ under fluorescent light $\left(9 \mu \mathrm{mol} \cdot \mathrm{m}^{-2} \cdot \mathrm{s}^{-1}\right)$.

Seeds were also treated with ethylene gas; in this case, 50 dry or preconditioned seeds (three replicates) were soaked in water in 30-ml Erlenmeyer flasks containing two layers of Whatman No.1 filter paper moistened with $1.5 \mathrm{ml}$ water. A calculated amount $\left(10 \mu \mathrm{l} \cdot \mathrm{liter}^{-1}\right)$ of ethylene gas was injected into flasks sealed with a rubber septum and the flasks were incubated at $35 \mathrm{C}$ for $12 \mathrm{~h}$.

ACC determination. One-hundred dry or preconditioned seeds or seedlings were extracted at room temperature with $80 \%$ methanol using a mortar and pestle. After being centrifuged at $3000 \mathrm{x}$ $g$ for $15 \mathrm{~min}$, the residue was resuspended in $80 \%$ methanol and recentrifuged. The supernatants were combined and concentrated to dryness in vacuo. The ACC content in the dried extract was determined by chemical degradation of ACC to ethylene according to Lizada and Yang (1979). Ethylene was determined by gas chromatography (Khan and Huang, 1988) using helium as a carrier gas and an oven temperature of $45 \mathrm{C}$. The efficiency of ACC conversion to ethylene by the seed extract was found to be $\approx 60 \%$. All experiments were repeated twice, with three replications.

Polyamine determination. Polyamines were determined by the procedure of Flores and Galston (1982) with some modifications. One-hundred dry or preconditioned seeds were ground in $2 \mathrm{ml}$ of $5 \%(\mathrm{v} / \mathrm{v})$ perchloric acid, and the extract was centrifuged at $27,000 \times g$ for $20 \mathrm{~min}$. "Free" polyamines in the supernatant were benzoylated. A $100-\mu \mathrm{l}$ portion of $5 \% \mathrm{HClO}_{4}$ extract was mixed with $400 \mu \mathrm{l} 2 \mathrm{~N} \mathrm{NaOH}$ in a 2-ml microcentrifuge tube. After the addition of $5 \mu$ benzoylchloride, the mixture was vortexed for $30 \mathrm{sec}$ and incubated at room temperature for $30 \mathrm{~min}$. This step was followed by the addition of $400 \mu \mathrm{l}$ of saturated $\mathrm{NaCl}$ solution and $400 \mu \mathrm{l}$ diethyl ether; the contents then were vortexed for $15 \mathrm{sec}$. After centrifugation in a microcentrifuge at $5000 \mathrm{rpm}$ for $5 \mathrm{~min}$, a 200 - or $100-\mu \mathrm{l}$ portion of the ether phase was collected and air-dried in a hood. The dried extract was redissolved in $200 \mu \mathrm{l}$ methanol (HPLC grade) and used to determine polyamine concentrations. Hydrochlorides of Spd, Put, spermine (Spm), and cadaverine (Cad) and 1-6-hexanediamine were used as standards and treated in a similar way. 1,6-Hexanediamine was used as an internal standard.

Waters M-45 solvent delivery system (Waters Assoc., Milford, Mass.) and Model 440 absorbance detector were used for HPLC analysis of polyamines. The solvent system was run isocratically at $65 \%(\mathrm{v} / \mathrm{v})$ aqueous methanol. A $4.6 \times 250-\mathrm{mm}$, 5 - $\mu$ m particle size, reverse-phase (C18) column (Beckman) was used to isolate benzoylated extracts for detection at $254 \mathrm{~nm}$.

\section{Results and Discussion}

Seedpreconditioning, relief of thermoinhibition, and ethylene biosynthesis. Untreated dry seeds held at 35C failed to germinate in water, but $6 \%$ and $7 \%$ germinated in ACC and ETH, respectively, during the 40 -h soak (Table 1). A progressive reversal of thermoinhibition occurred with an increase in preconditioning duration with moist Micro-Cel $\mathrm{E}$ at $15 \mathrm{C}$. After $4 \mathrm{~h}$, $31 \%$ of the seeds had germinated at $35 \mathrm{C}$ in the presence of ETH, whereas ACC had little effect. After $8 \mathrm{~h},>80 \%$ of the seeds germinated at $35 \mathrm{C}$ in the presence of ACC and ETH and only half that germinated in water. More than $90 \%$ germination
Table 1. Effect of duration of preconditioning on alleviation of thermoinhibition in lettuce seeds soaked in water, ACC, and ETH or exposed to ethylene.

\begin{tabular}{lcccc}
\hline \hline $\begin{array}{l}\text { Preconditioning } \\
\text { duration }(\mathrm{h})\end{array}$ & Water & ACC & ETH & Ethylene \\
\hline \multicolumn{4}{c}{ Germination } & at $35 C(\%)^{y}$ \\
0 (dry seeds) & 0 & $6 \pm 1.0$ & $7 \pm 2.8$ & -- \\
4 & 0 & $7 \pm 2.3$ & $31 \pm 4.8$ & $11 \pm 3.5$ \\
8 & $44 \pm 3.9$ & $83 \pm 2.4$ & $89 \pm 3.4$ & $76 \pm 0.5$ \\
12 & $79 \pm 4.9$ & $85 \pm 1.7$ & $89 \pm 3.1$ & $72 \pm 5.2$ \\
16 & $82 \pm 0.9$ & $94 \pm 1.7$ & $92+1.0$ & $85 \pm 1.3$ \\
20 & $93 \pm 2.2$ & $93 \pm 2.2$ & $94 \pm 2.2$ & $90 \pm 1.4$ \\
\hline
\end{tabular}

${ }^{2}$ Dry seeds $(0 \mathrm{~h}$ preconditioned) were germinated in water, $1 \mathrm{~mm} \mathrm{ACC}$, or $1 \mathrm{~mm} \mathrm{ETH} \mathrm{at} 35 \mathrm{C}$ for $40 \mathrm{~h}$. Preconditioned seeds were germinated in water, $1 \mathrm{~mm} \mathrm{ACC}$, or $1 \mathrm{~mm} \mathrm{ETH}$ for $24 \mathrm{~h}$ at 35C. Preconditioning was as follows: seeds were treated with Micro-Cel E for 4 to $20 \mathrm{~h}$ at $15 \mathrm{C}$ in the presence of water, $1 \mathrm{~mm} \mathrm{ACC}$, or $1 \mathrm{~mm} \mathrm{ETH}$. Micro-Cel $\mathrm{E}$ was removed by washing. Seeds preconditioned for 4 to $20 \mathrm{~h}$ in the presence of water were washed and exposed to $10 \mu \mathrm{l}$ ethylene/liter during a 12 -h soak in water at 35C.

'Data represent means \pm SD.

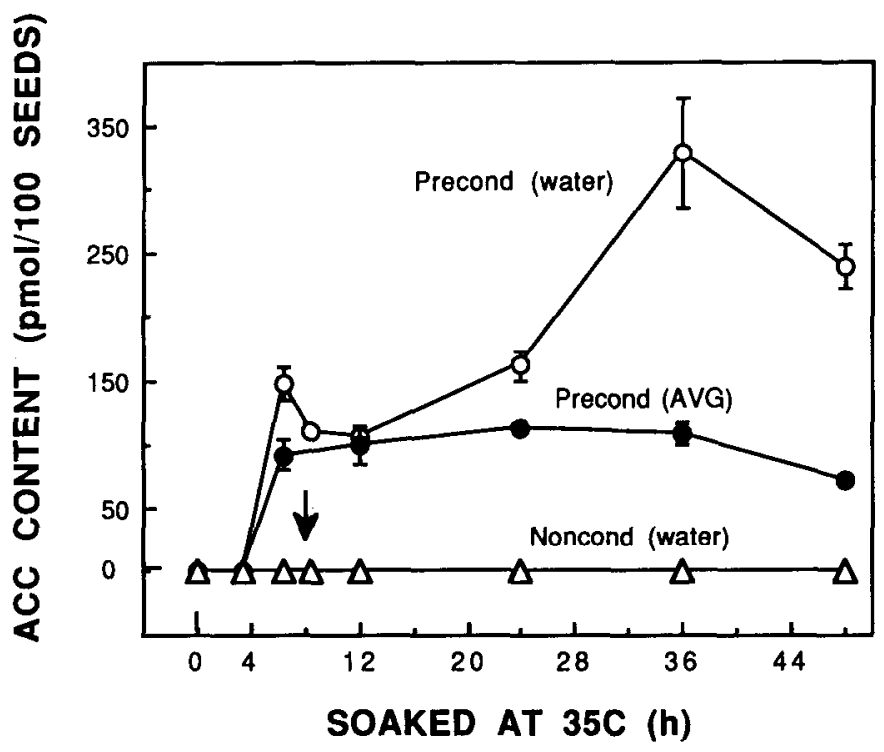

Fig. 1. Changes in ACC level in preconditioned seeds (soaked in prescence or absence of $1 \mathrm{~mm}$ AVG) and in nonconditioned lettuce seeds following transfer to 35C. Seeds were preconditioned for 20 $\mathrm{h}$ at $15 \mathrm{C}$ with moist Micro-Cel E, washed, and then germinated at $35 \mathrm{C}$ in water or AVG for $48 \mathrm{~h}$. Nonconditioned seeds were soaked directly in water at $35 \mathrm{C}$ for $48 \mathrm{~h}$. Arrow at $8 \mathrm{~h}$ of soaking time indicates beginning of germination in preconditioned (minus AVG) seeds. Nonconditioned seeds did not germinate at 35C. Bars represent SD.

at $35 \mathrm{C}$ occurred in water, ACC, ETH, or ethylene in seeds preconditioned for $20 \mathrm{~h}$.

When lettuce seeds were imbibed directly at 35C, ACC synthesis was not detectable (Fig. 1). However, when the seeds were preconditioned with Micro-Cel $\mathrm{E}$ for $20 \mathrm{~h}$ at $15 \mathrm{C}$ and then transferred to $35 \mathrm{C}$, a peak in $\mathrm{ACC}$ production occurred at 6.5 $\mathrm{h}$, before the beginning of germination at $8 \mathrm{~h}$ (shown by an arrow in Fig. 1; it took more than $16 \mathrm{~h}$ for germination to reach $80 \%$ to $90 \%$ ). Thereafter, the rate of ACC production declined. A second and larger peak of ACC was found after $36 \mathrm{~h}$, long after germination was completed. Adding AVG inhibited the pregermination ACC peak by $\approx 50 \%$ and the second ACC peak 
by $\approx 75 \%$ and continued to be inhibitory throughout the 48 -h soak at $35 \mathrm{C}$.

Application of $1 \mathrm{~mm} \mathrm{AVG}$ during preconditioning at $15 \mathrm{C}$ and germination at $35 \mathrm{C}$ or at $35 \mathrm{C}$ alone strongly inhibited $(50 \%$ to $70 \%$ ) germination at 35C (Table 2). The effectiveness of AVG was reduced when applied during preconditioning at $15 \mathrm{C}$, presumably due to some absorbance by Micro-Cel E. When applied directly (in the absence of Micro-Cel E) during preconditioning at $15 \mathrm{C}$, AVG was as effective in inhibiting lettuce seed germination at $35 \mathrm{C}$ as when present during both preconditioning and germination (Khan, 1992). The inhibitory effect was fully reversed by adding either $1 \mathrm{~mm}$ ACC or $10 \mathrm{~mm}$ ETH. Ethylene and ACC were equally effective in reversing the effect of AVG when applied only during soaking at 35C. Germination of preconditioned seeds at $25 \mathrm{C}$ was not influenced by the presence of AVG. This result is consistent with the previous report that AVG has no effect on germination at $25 \mathrm{C}$ even though it inhibits ethylene production; the requirement of $\mathrm{ACC}$ and ethylene for germination is induced at 35C (Khan and Prusinski, 1989). Unlike $\mathrm{AVG}, \mathrm{Co}^{+2}$ was relatively less effective in inhibiting germination at 35C (Table 3). Maximum inhibition occurred when it was present during both preconditioning and at 35C. It had little effect when applied alone during preconditioning. The inhibitory effect of $\mathrm{Co}^{+2}$ was effectively removed upon adding $10 \mathrm{~mm}$ ETH.

The ability of preconditioned lettuce seeds to rapidly synthesize ACC and respond to ACC and ethylene on transfer to $35 \mathrm{C}$ appears to be critical in alleviating thermoinhibition. This requirement is demonstrated by the following: a) dry seeds directly imbibed at $35 \mathrm{C}$ did not synthesize detectable $\mathrm{ACC}$ and showed little response to ACC or ETH (Table 1); b) no ACC was detected during preconditioning at $15 \mathrm{C}$ and up to $4 \mathrm{~h}$ at $35 \mathrm{C}$ (Fig. 1); c) some responsiveness to ETH or ethylene at $35 \mathrm{C}$ was acquired within $4 \mathrm{~h}$ of preconditioning at $15 \mathrm{C}$ and nearly full responsiveness to ACC, ETH, or ethylene after $8 \mathrm{~h}$, indicating that ACC use commences within $4 \mathrm{~h}$ of preconditioning and is completed in the next $4 \mathrm{~h}$ (Table 1); d) when

Table 2. Effect of AVG alone and in the presence of ACC, ETH, and ethylene on alleviation of thermoinhibition in lettuce seeds.

\begin{tabular}{|c|c|c|c|}
\hline \multirow[b]{2}{*}{ Treatment ${ }^{z}$} & \multicolumn{2}{|c|}{$35 \mathrm{C}$} & \multirow{2}{*}{$\frac{25 \mathrm{C}}{12 \mathrm{~h}}$} \\
\hline & $12 \mathrm{~h}$ & $24 \mathrm{~h}$ & \\
\hline & \multicolumn{3}{|c|}{ Germination $(\%)^{\nu}$} \\
\hline Preconditioned (untreated control) & $86 \pm 1$ & $87 \pm 0.8$ & $90 \pm 0.5$ \\
\hline \multicolumn{4}{|c|}{$\begin{array}{l}\text { Present during both preconditioning } \\
\text { and germination }\end{array}$} \\
\hline AVG & $19 \pm 0.8$ & $38 \pm 3.4$ & $91 \pm 1.2$ \\
\hline$A V G+A C C$ & $89 \pm 2.9$ & $93 \pm 2.3$ & -- \\
\hline AVG + ETH & $90 \pm 4.1$ & $94 \pm 0.6$ & $\cdots$ \\
\hline \multicolumn{4}{|l|}{ Present only during germination } \\
\hline AVG & $18 \pm 1.7$ & $41 \pm 2.0$ & $89 \pm 2.0$ \\
\hline$A V G+A C C$ & $88 \pm 1.0$ & $90 \pm 0.8$ & -- \\
\hline AVG + ethylene & $93 \pm 2.2$ & --- & -- \\
\hline \multicolumn{4}{|l|}{ Present only during preconditioning } \\
\hline AVG & $75 \pm 1.8$ & $81 \pm 1.2$ & -- \\
\hline $\mathrm{AVG}+\mathrm{ACC}$ & $87 \pm 1.2$ & $93 \pm 0.5$ & -- \\
\hline
\end{tabular}

${ }^{2}$ Seeds were treated with $1 \mathrm{~mm} \mathrm{AVG}$ alone or in combination with 1 mm ACC, $10 \mathrm{~mm} \mathrm{ETH}$, or $10 \mu \mathrm{l}$ ethylene/liter during $20 \mathrm{~h}$ of preconditioning at $15 \mathrm{C}$ with Micro-Gel E, during germination at $35 \mathrm{C}$, or at both times. Seeds treated with AVG alone were additionally germinated at $25 \mathrm{C}$ for $12 \mathrm{~h}$. Ethylene was applied during $12 \mathrm{~h}$ of germination at $35 \mathrm{C}$ in the presence of $1 \mathrm{~mm}$ AVG to seeds preconditioned at $15 \mathrm{C}$ in water for $20 \mathrm{~h}$.

'Data represent means $t \mathrm{SD}$.
Table 3. Effect of $\mathrm{CoCl}_{2}$ alone and in the presence of ETH on alleviation of thermoinhibition in lettuce seeds.

\begin{tabular}{lcc}
\hline \hline & \multicolumn{2}{c}{ Germination at $35 \mathrm{C}(\%)^{\mathrm{y}}$} \\
\cline { 2 - 3 } Treatment & \multicolumn{1}{c}{$12 \mathrm{~h}$} & $24 \mathrm{~h}$ \\
\hline Preconditioned (untreated control) & $87 \pm 2.0$ & $87 \pm 1.3$ \\
Present during both preconditioning & & \\
$\quad$ and germination & $73 \pm 2.0$ & $79 \pm 1.1$ \\
$\quad \mathrm{CoCl}_{2}$ & $91 \pm 1.3$ & $93 \pm 1.5$ \\
$\quad \mathrm{CoCl}_{2}+$ ETH & $82 \pm 2.0$ & $84 \pm 0.3$ \\
Present only during preconditioning & $90 \pm 0.9$ & $94 \pm 1.2$ \\
$\quad \mathrm{CoCl}_{2}$ & $\mathrm{CoCl}_{2}+$ ETH &
\end{tabular}

${ }^{2}$ Seeds were treated with $1 \mathrm{~mm} \mathrm{CoCl}_{2}$ and $10 \mathrm{~mm}$ ETH during $20 \mathrm{~h}$ of preconditioning at $15 \mathrm{C}$ and during preconditioning and germination at $35 \mathrm{C}$.

${ }^{y}$ Data represent means $\pm S D$.

preconditioned seeds were transferred to $35 \mathrm{C}$, ACC level peaked at $\approx 6.5 \mathrm{~h}$ of imbibition, i.e., before germination, which began after $8 \mathrm{~h}$ (Fig. 1); e) AVG was effective in inhibiting ACC production and germination, and the effects were reversed by adding exogenous ACC, ETH, or ethylene (Fig. 1, Table 2); and $\mathrm{f}) \mathrm{Co}^{+2}$ partially inhibited germination at $35 \mathrm{C}$, and germination was fully restored by adding ETH (Table 3). As the effect of AVG on germination was fully reversible by ETH or ethylene (Table 2), $\mathrm{Co}^{+2}$ may only partially affect the ACC-to-ethylene step.

Activation or synthesis of the ethylene-forming enzyme (EFE) followed by that of ACC synthase may occur during early hours of preconditioning. This sequence is indicated by the fact that lettuce seeds responded to ethylene at $35 \mathrm{C}$ after $4 \mathrm{~h}$ and to ACC after $8 \mathrm{~h}$ of preconditioning (Table 1). Inhibition of ethylene production at high temperature and by salinity stress and an enhancement in ACC use by cytokinin under these conditions have been reported in lettuce seeds (Khan and Huang, 1988; Khan and Prusinski, 1989). Oxidative changes might occur during seed preconditioning that could enhance EFE activity. Thus, cytokinin or cytokinin-like factors may be produced during the early preconditioning period and participate in thermotolerance via enhanced ACC use resulting from activation or synthesis of EFE or ACC oxidase.

Improved performance of preconditioned lettuce seeds at high temperature is related to high vigor and greater capacity to produce ethylene. A preplant conditioning at $15 \mathrm{C}$ conferred germinability at $35 \mathrm{C}$ to high-vigor but not to low-vigor lettuce seeds (Perkins-Veazie and Cantliffe, 1984), presumably due to a greater ability of the former to produce ethylene. The ability of lettuce seeds to germinate at high temperature and under other stresses has been correlated with the ability to produce ethylene (Prusinski and Khan, 1990). Ability of wheat (Triticum aestivum L.) seeds to tolerate high temperature by prior imbibition (a preconditioning treatment) for up to $12 \mathrm{~h}$ was weaker in lowthan in high-vigor seeds (Helm et al., 1989). Lettuce seeds preconditioned at $15 \mathrm{C}$ in a low-water-potential polyethylene glycol solution for $24 \mathrm{~h}$ developed a high germination potential at $35 \mathrm{C}$ (Khan, 1992). Thus, preconditioning is intimately related to seed vigor, thermotolerance, and improved ethylene biosynthesis.

Relief of thermoinhibition and polyamine biosynthesis. The major polyamines in the dry lettuce seeds were Put $(\approx 10 \mu \mathrm{g} /$ 100 seeds) and Spd $(\approx 30 \mu \mathrm{g} / 100$ seeds). Trace amounts of Spm appeared only after germination (data not shown). No Cad or other polyamines were detected. The amount of Spd increased 
rogressively from the time the preconditioned seeds were transferred to $35 \mathrm{C}$, whereas that of Put increased after the preconditioned seeds had germinated at 35C (Figs. 2-4). Adding difluoromethylarginine (DFMA), a specific inhibitor of arginine decarboxylase, to preconditioned seeds inhibited the increase in both Put and Spd. The inhibition occurred $24 \mathrm{~h}$ after transfer of seeds to $35 \mathrm{C}$, and the intensity of inhibition increased progressively up to $48 \mathrm{~h}$ (Fig. 2). Unlike DFMA, adding difluoromethylornithine (DFMO), a specific inhibitor of ornithine decarboxylase, failed to inhibit the increase in Put and Spd contents (Fig. 3). The inhibitor of Spd biosynthesis cyclohexylammonium sulfate (CHAS), strongly inhibited the increase in

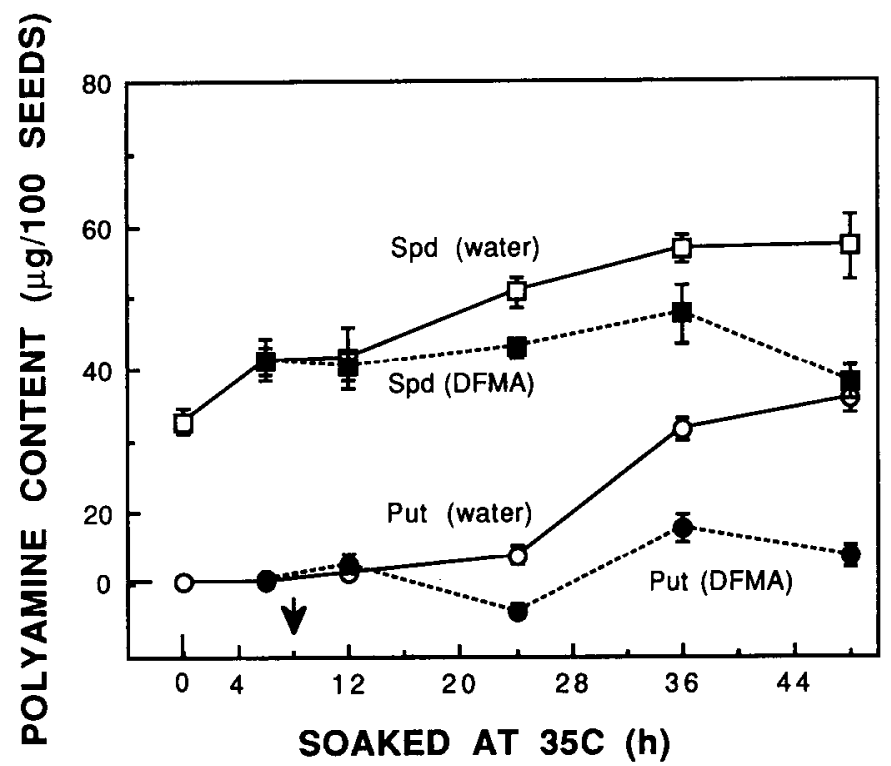

Fig. 2. Changes in Put and Spd levels in the presence or absence of 2 mM DFMA in preconditioned lettuce seeds following transfer to $3 \%$. Arrow indicates beginning of germination. Other details as in Fig. 1.

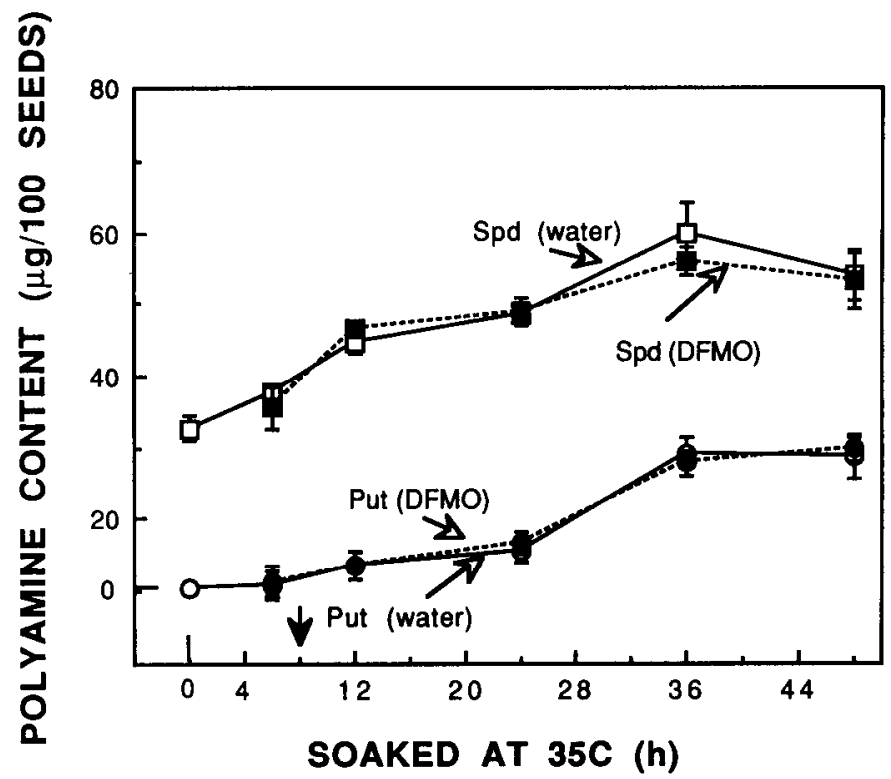

Fig. 3. Changes in Put and Spd levels in the presence or absence of $2 \mathrm{~mm}$ DFMO in preconditioned lettuce seeds following transfer to 35C. A solid arrow at $8 \mathrm{~h}$ soaking time indicates beginning of germination. Other details as in Fig. 1.

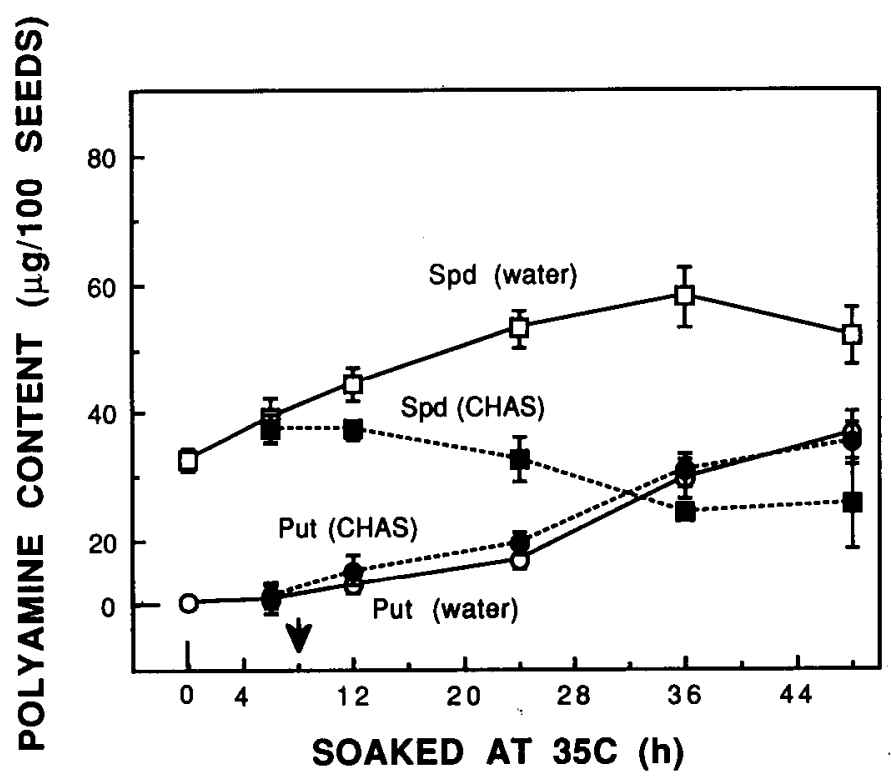

Fig. 4. Changes in Put and Spd levels in the presence or absence of 1 mм CHAS in preconditioned lettuce seeds following transfer to 35C. Arrow indicates beginning of germination. Other details as in Fig. 1.

Spd content (Fig. 4). As expected, CHAS had no effect on Put. None of the polyamine biosynthesis inhibitors, DFMA, DFMO, or CHAS, inhibited germination of lettuce seeds when applied during preconditioning at $35 \mathrm{C}$ or at both times (data not shown).

Biosynthesis of Put and Spd during soaking at 35C may be via the arginine decarboxylase rather than the ornithine decarboxylase pathway, as DFMO, the specific inhibitor of ornithine decarboxylase, had no effect on either Put or Spd levels. Ornithine decarboxylase is the key enzyme involved in cell division (Bagni et al., 1983), while arginine decarboxylase has a preferential role in stress responses of plants (Slocum et al., 1984; Smith, 1970). Germination at 35C in preconditioned lettuce seeds has been shown to occur via cell elongation (Cantliffe et al., 1984). These reported observations may partly explain why DFMO has little effect on Put and Spd levels during germination of preconditioned seeds at $35 \mathrm{C}$. We, therefore, hypothesize that ornithine decarboxylase does not participate in the germination of lettuce seeds at elevated temperature. However, to confirm this hypothesis, an analysis of ornithine decarboxylase activity is warranted.

Our data show that an increase in polyamines is not associated with the relief of thermoinhibition in preconditioned lettuce seeds. As the inhibitors did not decrease polyamines to levels below those of controls, polyamines might still be needed in some way in modulating germination at high temperature.

\section{Literature Cited}

Abeles, F.B. 1986. Role of ethylene in Lactuca sativa cv. 'Grand Rapids' seed germination. Plant Physiol. 81:780-787.

Bagni, N., P. Barbieri, and P. Torrigiani. 1983. Polyamine titer and biosynthetic enzymes during tuber formation of Helianthus tuberosus. J. Plant Growth Regulat. 2:177-184.

Cantliffe, D.J., J.M. Fischer, and T.A. Nell. 1984. Mechanism of seed priming in circumventing thermodormancy in lettuce. Plant Physiol. 75:290-294.

Das, S., R. Basu, and B. Ghosh. 1987. Heat stress induced polyamine accumulation in cereal seedlings. Plant Physiol. Biochem. 14:108116.

Flares, H.E. and A.W. Galston. 1982. Analysis of polyamines in higher 
plants by high performance liquid chromatography. Plant Physiol. 69:701-706.

Helm, K.W., N.S. Petersen, and R.H. Abernethy. 1989. Heat shock response of germinating embryos of wheat. Plant Physiol. 90:598605.

Khan, A.A. 1980/1981. Hormonal regulation of primary and secondary seed dormancy. Israel J. Bot. 29:207-224.

Khan, A.A. 1992. Preplant physiological seed conditioning. Hort. Rev. 13:131-181.

Khan, A.A. and X.L. Huang. 1988. Synergistic enhancement of ethylene production and germination with kinetin and 1-aminocyclopropane-1-carboxylic acid in lettuce seeds exposed to salinity stress. Plant Physiol. 87:847-852.

Khan, A.A., H. Miura, J. Prusinski, and S. Ilyas. 1990. Matriconditioning of seeds to improve emergence. Proc. Symp. Stand Establishment of Horticultural Crops, Minneapolis, 4-6 Apr. 1990. p. 19-38.

Khan, A.A. and J. Prusinski. 1989. Kinetin enhanced 1-aminocyclopropane-1-carboxylic acid utilization during alleviation of high temperature stress in lettuce seeds. Plant Physiol. 91:733-737.

Lizada, M.C.C. and S.F. Yang. 1979. A simple and sensitive assay for 1-aminocyclopropane-1-carboxylic acid. Anal. Biochem. 100:140145.

Miyazaki, J.H. and SF. Yang. 1987. The methionine salvage pathway in relation to ethylene and polyamine biosynthesis. Physiol. Plant. 69:366-370.
Perkins-Veazie, P. and D.J. Cantliffe. 1984. Need for high quality seed for effective priming to overcome thermodormancy. J. Amer. Soc. Hort. Sci. 109:368-372.

Prusinski, J. and A.A. Khan. 1990. Relationship of ethylene production to stress alleviation in seeds of lettuce cultivars. J. Amer. Soc. Hort. Sci. 115:294-298.

Rabe, E. 1990. Stress physiology: The functional significance of the accumulation of nitrogen-containing compounds. J. Hort. Sci. 65:231243.

Saini, H.S., E.D. Consolation, P.K. Basi, and M.S. Spencer. 1986. Requirements for ethylene synthesis and action during relief of thermoinhibition of lettuce seed germination by combinations of gibberellic acid, kinetin and carbon dioxide. Plant Physiol. 81:950953.

Scoccianti, V., P. Torrigiani, and N. Bagni. 1990. Distribution of diamine oxidase activity and polyamine pattern in bean and soybean seedlings at different stages of germination. Physiol. Plant. 80:515519 .

Slocum, R.D., R. Kaur-Sawhney, and A.W. Galston. 1984. The physiology and biochemistry of polyamines in plants. Arch. Biochem. Biophys. 235:283-303.

Smith, T.A. 1970. The biosynthesis and metabolism of putrescine in higher plant. Ann. N.Y. Acad. Sci. 71:988-1001.

Torrigiani, P., V. Scoccianti, and N. Bagni. 1988 Polyamine oxidase activity and polyamine content in maize during seed germination. Physiol. Plant. 74:427-432. 